\title{
INFLUENCE OF CORRUGATION DEPTH ON LATERAL STABILITY OF COLD-FORMED STEEL BEAMS OF CORRUGATED WEBS
}

\author{
Viorel UNGUREANU*, Dan DUBINA* \\ *Department of Steel Structures and Structural Mechanics, Politehnica University of Timisoara, Romania \\ Laboratory of Steel Structures, Romanian Academy - Timisoara Branch, Romania \\ viorel.ungureanu@upt.ro, dan.dubina@upt.ro
}

received 6 September 2015, revised 10 May 2016, accepted 12 May 2016

\begin{abstract}
The beams of thin corrugated web afford a significant weight reduction compared with hot-rolled or welded ones. In the initial solutions, the flanges are made of flat plates, welded to the sinusoidal web sheet, requiring a specific welding technology. A new solution is proposed by the authors, in which the beam is composed by a web of trapezoidal cold-formed steel sheet and flanges of back-to-back lipped channel sections. For connecting flanges to the web self-drilling screws are used. The paper summarizes the experimental and numerical investigations carried out at the CEMSIG Research Centre (www.ct.upt.ro/centre/cemsig/) of the Politehnica University of Timisoara and, at the end, presents the influence of corrugation depth of web on the lateral stability of the beams.
\end{abstract}

Key words: Corrugated Web Beam, Cold-Formed Steel Solution, Discrete Fasteners, Self-Drilling Screws, Experimental Investigation

\section{INTRODUCTION}

Corrugated web girders represent a relatively new structural system emerged in the past two decades in Europe, particularly in Germany and Austria. Increased interest for this solution was observed for the main frames of single-storey steel buildings and in steel bridges. The technical solution consists in using a sinusoidal web sheet which is welded to the flat plates used for flanges, a specific welding technology being applied.

The main benefits of this type of elements are that the corrugated webs increase the beam's stability against local buckling and also against lateral-torsional buckling, which may result in a more economical design if compares with flat web with stiffeners. Furthermore, the use of thinner webs results in lower material cost, with an estimated cost savings of $10-30 \%$ in comparison with conventional fabricated sections and more than $30 \%$ compared with standard hot-rolled beams. The buckling resistance of the sinusoidal corrugated steel sheet used for webs, which is very thin (1.5-3 mm), is comparable with plane webs of $12 \mathrm{~mm}$ thickness or more.

A new technological solution composed by webs made of trapezoidal cold-formed steel sheets and flanges of built-up cold-formed steel profiles (e.g. back-to-back lipped channel sections or angles with turn lips) has been proposed by the authors Dubina et al., $(2013,2015)$. The connections between flanges and web can be done with self-drilling screws or by spot welding. Compared with the traditional solution, where the sinusoidal web sheet is continuous, in this case the width of corrugated sheets that compose the web is approximately $1000 \mathrm{~mm}$. Consequently, seam connections are needed for providing the continuity of the web. This ensemble, i.e. seam connections - two overlapped corrugated sheets, acts as web stiffeners, increasing resistance under transverse loads, of particular interest in the locations of purlin supports.
Also, it is easy to be observed that the new solution, as a whole, is $100 \%$ composed by cold-formed steel elements, avoiding the combination of two types of steel products, i.e. cold-formed for webs and hot-rolled for flanges as presented before (www.zeman-steel.com). Moreover, high protection to corrosion due to the fact that all components are galvanized is a major advantage.

Thin new solution can be used as roof girders, frame bearing structures (also multi-span and multi-storey) and short span pedestrian bridges. It is expected from this solution to cover medium spans up to $24 \mathrm{~m}$ length. They also can be a reliable alternative to purlins and secondary beams where these have to cover large bays, instead of using steel trusses.

A beam with corrugated web behaves similarly to a lattice girder, in which the bending moments and applied forces are transferred via flanges only, while the transverse forces are transferred through the diagonals and verticals of the lattice girder, in this case the corrugated web. The dimensioning of corrugated web beams is ruled by Annex D of the EN 1993-1-5:2006, together with specific aspects of EN 1993-1-1 and EN 1993-1-3.

The main aim of present study is to complete the previous studies of authors with an investigation of sensitivity of webs to distortion of corrugations when the size of corrugations increases.

\section{LITERATURE REVIEW}

Several types of built-up cold-formed steel beams prepared for industrialised fabrication have been experimentally investigated. For these beams, bolts, screws or spot/laser welding are used as fastening technologies.

In 2000, BEN-VAUTIER S.P.A., Italy (WO 00/17463), patented a modular $\mathrm{H}$-beam comprises one or more modules, each formed of two half-structural parts of two pieces of structural steel, 
forming each a thin sheet, comprising a central part or core and lateral half-flanges. The half-flanges form gaps, inside which plates are introduced in order to strengthen the flanges of the beam, which constitute the regions more subjected to bending stresses.

Zhao (2005) at Queensland University of Technology initiated a research program to investigate the structural behaviour and design of hollow flange beam sections as compression members. He used rectangular hollow flanges and various manufacturing methods such as spot welding, self-pierced riveting and screw fastening to form Rectangular Hollow Flange Beam (RHFB) sections from a single steel strip. It was observed that the type of fastening and spacing does not affect the member compression capacity significantly. However, the structural behaviour and design of RHFB as flexural members will be different and therefore further investigations are needed to identify their failure modes and develop suitable design rules.

Wanniarachchi (2005) extended the work of Zhao (2005) and developed a new cold-formed steel beam with two rectangular hollow flanges rigid in torsion and a slender web formed using intermittent screw fastening to enhance the flexural capacity while maintaining a minimum fabrication cost. His research was focused on the flexural behaviour and design of cold-formed steel beams with rectangular hollow flanges (RHFB) made of separately formed flanges and web connected by simple screw fastening. He has found that intermittent screw fastening method appears to be structurally adequate and minimises the fabrication cost.

Landolfo et al. (2008) evaluated the applicability of built-up cold-formed steel beams assembled by laser welding and assessed the load bearing capacity of the assembled beams. The I-section with hollow flanges is fabricated from two back-to-back special C-profiles. The two profiles are joined with connections which are located on the web and on the flanges. Two reinforcing plates are placed inside the top and bottom hollow flanges of the I-section, providing an additional connection system between the two C-profiles.

A very important aspect related to the cold-formed steel is the connecting technique. Briskham et al. (2006) performed a comparative study on of self-pierce riveting, resistance spot welding and spot friction joining for aluminium automotive sheet. Quantitative comparisons have been made on the basis of tensile strength (shear and peel), process time, equipment price and running cost. The results identified resistance spot welding as a more economically favourable option than self-pierce riveting or spot friction joining for the task of producing the majority of the joints. The analysis indicates that it is the ongoing cost of the rivets that makes self-pierce riveting the most expensive process. For resistance spot welding, the largest cost factors identified were energy consumption and frequency of electrode replacement. Although the material is aluminium, similar conclusions can be drawn for steel too.

Guenfoud et al. (2010) tested welded specimens fabricated through one, two or four layers of steel sheets with thicknesses ranging from $0.76 \mathrm{~mm}$ to $1.52 \mathrm{~mm}$. A total of 72 tension tests and 107 shear tests were completed. The idea was the initiation of a research program on the shear resistance and tension resistance of multi-layer arc spot welds. They found that the type of electrode, high current setting and proper welding technique affect the quality of arc-spot welds in multi-layer connections, and a lower limit for the net effective weld diameter was proposed.

Snow (2008) conducted a similar research in order to establish a relationship between arc spot weld shear strength and the arc time used while forming the weld. In this case the arc times were broken down into three separate categories. The first category consisted of full-time welds, the second 2/3-time welds, and the third 1/3-time welds. Testing was performed on steel gauge sheets of $0.85 \mathrm{~mm}, 1 \mathrm{~mm}, 1.3 \mathrm{~mm}$ and $1.6 \mathrm{~mm}$. Each gauge material was tested in single-, double- and four-layer configurations. Two types of diameter arc spot welds were tested. Comparisons were made between shear strength and weld geometry, including average diameter, effective diameter and penetration. The research has proven that arc time has a tremendous influence on arc spot weld shear strength.

A wide experimental investigation on laser welded connections based on both lap-shear and tension tests were performed at the University of Naples (2009). The experimental programme was designed in order to evaluate the effects of different parameters on the strength and ultimate displacement of the selected connections. The results of the experimental tests were compared with the predicted resistance values according to Eurocode 3, with the aim of validating for laser welding the mechanical models provided for spot welds.

A lot of work has been done to study the shear capacity (Yi et al., 2008; Moon et al., 2008; Sause and Braxtan, 2011) and the behaviour under patch loading of steel beams with corrugated web (Abbas et al., 2006, 2007). In what concerns the bending behaviour it was observed that the contribution of the web to the ultimate moment capacity of a beam with corrugated web is negligible, and the ultimate moment capacity is based on the flange yield stress. The effect of the corrugation profiles of the web on the lateral-torsional buckling strength of I-girders was also studied (Kazemi et al., 2010; Jiho et al., 2009; Moon et al., 2013; Kövesdi, 2012). Pasternak et al. (2010) presented a new proposal for Annex D of EN 1993-1-5:2006.

Probably, the first built-up steel girder using corrugated sheets as web elements and cold-formed sections for flanges is the Macomber Panlweb girder appeared on the market around the '70s. The Macomber Panlweb girder consists of $1.9 \mathrm{~mm}$ to 3.8 $\mathrm{mm}$ thickness of the corrugated web for depths of 0.51 to $1.02 \mathrm{~m}$ (US3444664). This solution applies shallow VV-section for flanges, which make difficult enough the installing of flange-to-web fasteners.

The first attempt of the authors of this paper related to this type of beams $100 \%$ composed by cold-formed steel elements was a numerical study (Neagoie et al., 2005) in order to prove the efficiency of such solution against cold-formed steel trusses.

A similar solution has been proposed and analysed in the frame of PRECASTEEL project (RFSR-CT-2007-00038), but using blind rivets as seam fasteners for the corrugated web and bolts for web-to-flange connections. For flanges, back-to-back lipped channel or two types of hat-sections have been used. Deep corrugation web sheeting of longitudinal intermediate stiffeners have been applied in this solution. However, looking to the test results, one observes the sensitivity to distortion of corrugation still remain high.

\section{EXPERIMENTAL TESTS}

\subsection{Specimens, test procedure and test results}

The experimental program was carried out at the CEMSIG Research Centre (http://www.ct.upt.ro/en/centre/cemsig) of the Politehnica University of Timisoara. Five beams with corrugated 
webs (CWB) with a span of $5157 \mathrm{~mm}$ and a height of $600 \mathrm{~mm}$ have been tested (see Tab. 1), considering different arrangements for self-drilling screws and shear panels [1,2].

Fig. 1(a) presents the components of the CWB-1 beam with corrugated web (standard solution), i.e.:

- back-to-back lipped channel sections for flanges 2×C120/2.0;

- corrugated web with the corrugation depth of $43 \mathrm{~mm}$ and the thickness of $0.7 \mathrm{~mm}-\mathrm{A} 45 / 0.7$;

- reinforcing shear panels - plates of $1 \mathrm{~mm}$ thickness and 830 $\mathrm{mm}$ length, at the beam ends where the shear force is maximum;

- reinforcing U150/2.0 profiles used under the load application points, to avoid excessive local deformations;

- self-drilling screws for flange-to-web connection - STP$6.3 \times 25$;

- self-drilling screws for shear plates to end support - STP$5.5 \times 25$;

- self-drilling screws as seam fasteners for corrugated webs STT-4.8×20;

- bolts M12 class 8.8 for flanges to the end support connection.

Tab. 1. Types of specimens

\begin{tabular}{|c|l|}
\hline Code & Description \\
\hline CWB-1 & $\begin{array}{l}\text { Standard solution: flange-to-web connection in } \\
\text { every corrugations and uniformly distributed seam } \\
\text { fasteners }\end{array}$ \\
\hline CWB-2 & $\begin{array}{l}\text { Standard solution + supplementary lipped channel } \\
\text { sections under the load application points }\end{array}$ \\
\hline CWB-3 & $\begin{array}{l}\text { Optimized solution by adapting the flange-to-web } \\
\text { connections according to the distribution of shear } \\
\text { stresses (connections at each second corrugations } \\
\text { where the shear force decreases) }\end{array}$ \\
\hline CWB-4 & $\begin{array}{l}\text { Optimized solution by eliminating shear panels and } \\
\text { doubling of corrugated webs in the zones with high } \\
\text { shear forces }\end{array}$ \\
\hline CWB-5 & $\begin{array}{l}\text { Optimized solution by adapting both the flange-to- } \\
\text { web connections and seam fasteners to the distri- } \\
\text { bution of shear stresses }\end{array}$ \\
\hline
\end{tabular}

(a)

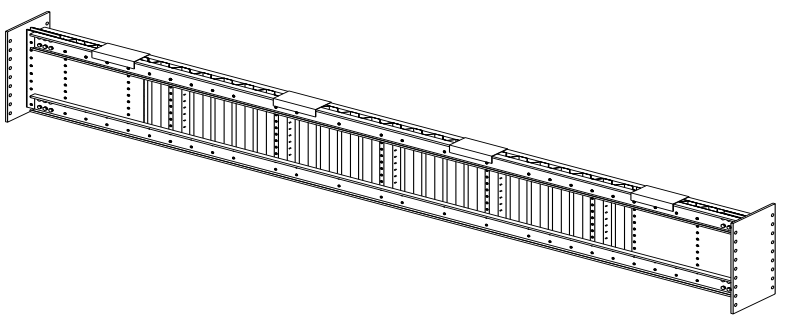

(b)

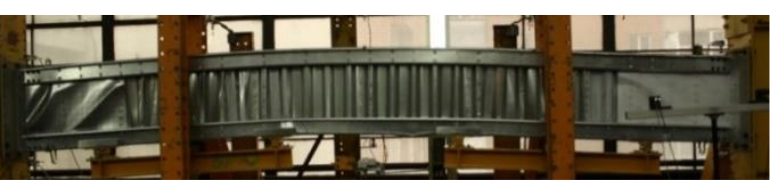

(c)

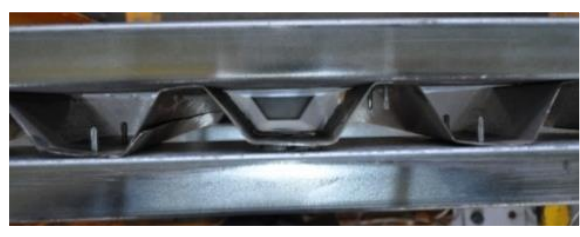

Fig. 1. (a) Configuration of the specimens; (b) Deformed shape of CWB- 5 beam at failure; (c) Distortion of the web corrugation
Fig. 2 presents the experimental arrangement. Six points bending tests, monotonically conducted, were applied for each specimen with a loading velocity of $2 \mathrm{~mm} / \mathrm{min}$.

Dubina et al. $(2013,2015)$ show detailed information related to the behaviour of each tested specimen, including the initial stiffness, $K_{0-E x p}$ and maximum load $F_{\text {max }}$, as well as the failure mode. These values are summarised in Tab. 4 . Fig. 1 (b,c) show, as an exemplification, the deformed shape of the CWB- 5 beam at collapse and the distortion of the web corrugation in the region with the reduced number of screws.
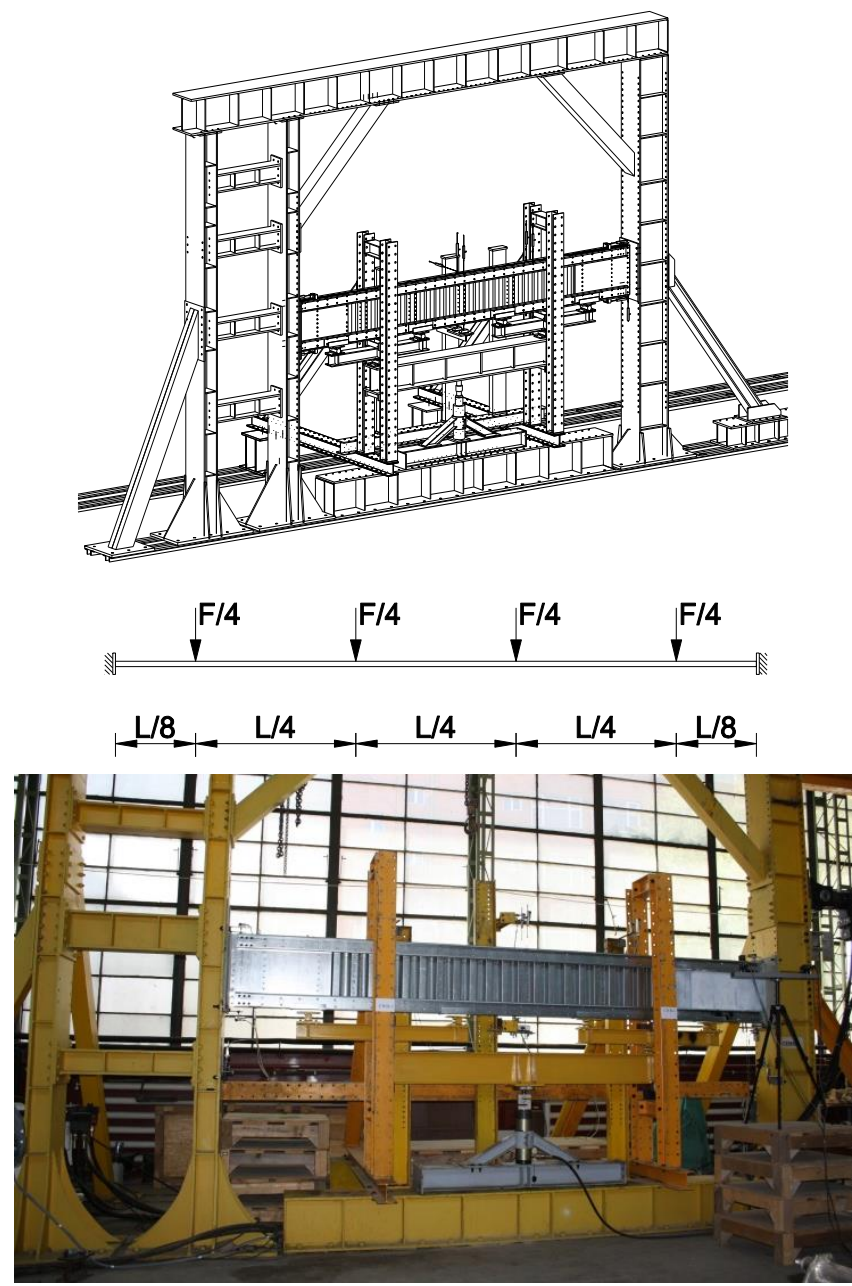

Fig. 2. Experimental arrangement

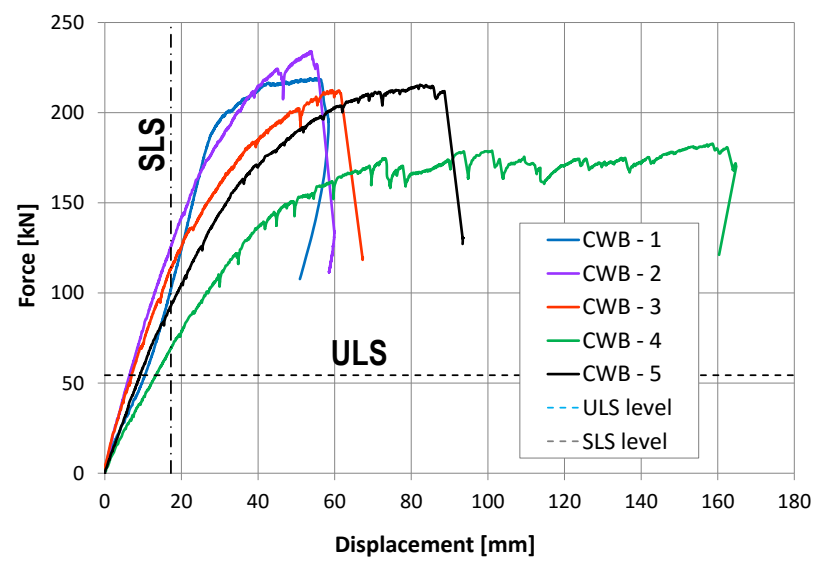

Fig. 3. Load-displacement curves for the tested specimens 
Finally, Fig. 3 shows, comparatively, the load-displacement curves for all five specimens, together with the ultimate (ULS) and serviceability limit state (SLS) levels.

The full-scale testing program was completed with tensile tests to determine both the material properties for beam components and the behaviour of connections.

\subsection{Material properties and connections behaviour}

In order to determine the mechanical properties of the CWB components, a set of samples were cut out from the lipped channels, corrugated sheet, both from the flat regions and corners and reinforcing shear panels, according to EN ISO 6892-1:2009 specifications, as shown in Fig. 4. Tab. 2 presents the mean values, standard deviations and the characteristic values for yield and ultimate strengths for the above samples. The following abbreviations for coupons have been used: BM-CF coupon cut from the flange of the lipped channel; BM-CW coupon cut from the web of the lipped channel; CM-CF coupon cut from the flange-web corner of the lipped channel; CM-CW coupon cut from the flat region of the corrugated web; BM-SP coupon cut from the shear panel.
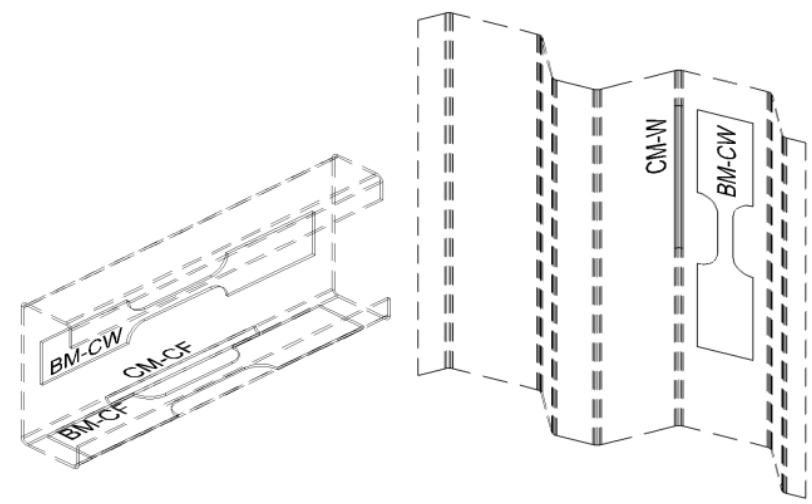

Fig. 4. Samples cut from flat regions and corners

Tab. 2. Yield and ultimate strengths of coupons cut from lipped channels, corrugate sheet and shear panel

\begin{tabular}{|c|c|c|c|c|c|c|}
\hline Type & $\begin{array}{c}f_{\text {yM }} \\
{[\mathrm{MPa}]}\end{array}$ & $\begin{array}{c}\mathbf{f}_{\mathrm{um}} \\
{[\mathrm{MPa}]}\end{array}$ & $\mathbf{S}_{\mathrm{fy}}$ & $\mathbf{S}_{\text {flu }}$ & $\begin{array}{c}\mathrm{f}_{\mathrm{yk}} \\
{[\mathrm{MPa}]}\end{array}$ & $\begin{array}{c}\mathrm{f}_{\mathrm{uk}} \\
{[\mathrm{MPa}]}\end{array}$ \\
\hline BM-CF & 438.74 & 517.06 & 5.69 & 2.46 & 425.48 & 511.33 \\
\hline BM-CW & 441.65 & 521.86 & 25.53 & 3.48 & 382.16 & 513.05 \\
\hline CM-CF & 521.64 & 585.07 & 9.89 & 9.69 & 498.6 & 562.49 \\
\hline CM-CW & 358.42 & 419.59 & 4.09 & 2.48 & 348.9 & 413.81 \\
\hline BM-SP & 349.41 & 394.75 & 12.67 & 10.89 & 319.89 & 369.37 \\
\hline
\end{tabular}

Six types of connections were tested according to Publication 124 of ECCS [29], at a loading velocity of $1 \mathrm{~mm} / \mathrm{min}$, i.e.:

- T1-1.4 seam fasteners for corrugated sheets;

- T2-1.7, seam fasteners for shear plates and corrugated sheets;

- T3-3.7, self-drilling screws for shear plates and flanges;

- T4-9.0, self-drilling screws for shear plates and end supports;

- T5-11.0, bolts for flanges to end-supports;

- T6-2.7, self-drilling screws for flanges to corrugated webs at mid-span,

in order to determine the behaviour of all types of connections found in the beam (see Tab. 3 and Fig. 5) (Abbas et al., 2007).

Tab. 3. Types of tested connections

\begin{tabular}{|c|c|c|c|c|c|}
\hline Name & $\mathbf{t}_{1}[\mathrm{~mm}]$ & $\begin{array}{c}\mathbf{t}_{2} \\
{[\mathrm{~mm}]}\end{array}$ & $\begin{array}{c}\text { No. of } \\
\text { tests }\end{array}$ & $\begin{array}{c}\mathbf{d}_{\text {nom }} \\
{[\mathrm{mm}]}\end{array}$ & Name \\
\hline $\mathrm{T} 1-1.4$ & 0.7 & 0.7 & 6 & 4.8 & $\mathrm{~T} 1-1.4$ \\
\hline $\mathrm{T} 2-1.7$ & 1.0 & 0.7 & 5 & 4.8 & $\mathrm{~T} 2-1.7$ \\
\hline $\mathrm{T} 3-3.7$ & $2.0+1.0$ & 0.7 & 6 & 6.3 & $\mathrm{~T} 3-3.7$ \\
\hline $\mathrm{T} 4-9.0$ & 1.0 & 8.0 & 5 & 5.5 & $\mathrm{~T} 4-9.0$ \\
\hline $\mathrm{T} 5-11.0$ & $2.0+1.0$ & 8.0 & 5 & $\mathrm{M} 12$ & $\mathrm{~T} 5-11.0$ \\
\hline $\mathrm{T} 6-2.7$ & 2.0 & 0.7 & 10 & 6.3 & $\mathrm{~T} 6-2.7$ \\
\hline
\end{tabular}

\section{NUMERICAL MODEL CALIBRATION AND VALIDATION}

Numerical models applied to simulate the behaviour of members experimentally tested have been created using the commercial FE program ABAQUS/CAE v.6.7.1. Rectangular 4-noded shell elements with reduced integration (S4R) were used to model the thin-walled components. CONN3D2 element types, with 2 nodes and 6 DOF per node, have been used to model the self-drilling screws and bolts. RB3D2 elements were used as rigid body for load transfer and multi-point constrain beam (MPC-Beam) for DOF coupling between groups of specified nodes.

The material behaviour used for numerical modelling was in accordance with the recorded curves from tensile tests from coupons cut over the cross-section of component elements (see Tab. 2). Self-drilling screws and bolts were introduced using CONN3D2 element type according to the mean values recorded from tests of each type of connection (see Fig. 5).

General contact with the following parameters have been used, i.e. (1) on normal direction - hard contact; (2) on transversal direction $-a$ friction coefficient of $\mu=0.1$. Finally, as initial imperfections, the first 3 eigen modes from a linear bucking analysis have been used.

Fig. 6 presents comparatively the FEM and experimental loaddisplacement curves for the five beams, while Tab. 4 shows comparatively, for each specimen, the initial stiffness and ultimate load obtained experimentally and via numerical simulations. Significant work on girders with corrugated web has been done. An extended literature review will be presented on the following.

Tab. 4. Initial stiffness and ultimate load: FEM vs. experimental results

\begin{tabular}{|c|c|c|c|c|}
\hline $\begin{array}{c}\text { Beam } \\
\text { type }\end{array}$ & $\begin{array}{c}\mathrm{K}_{\mathbf{0} \text {-Exp }} \\
(\mathbf{N} / \mathbf{m m})\end{array}$ & $\begin{array}{c}\mathrm{K}_{\mathbf{0} \text {-FEM }} \\
(\mathbf{N} / \mathbf{m m})\end{array}$ & $\begin{array}{c}\mathbf{F}_{\text {max-Exp }} \\
(\mathbf{k N})\end{array}$ & $\begin{array}{c}\mathbf{F}_{\text {max-FEM }} \\
(\mathbf{k N})\end{array}$ \\
\hline CWB-1 & 6862.2 & 7721.1 & 218.9 & 225.9 \\
\hline CWB-2 & 7831.5 & 7834.6 & 231.3 & 229.5 \\
\hline CWB-3 & 7184.9 & 6819.3 & 209.5 & 205.8 \\
\hline CWB-4 & 3985.0 & 4932.0 & 181.9 & 223.5 \\
\hline CWB-5 & 5516.2 & 6594.9 & 214.6 & 216.0 \\
\hline
\end{tabular}

The results obtained via numerical simulations show that the behaviour and maximum load accurately replicate the experimental tests. In case of CWB-4 beam the numerical results are $23 \%$ higher than experimental one. The reason could be the higher contribution of shear in the end panels; in this case there are no stiffening shear plates. 
Influence of Corrugation Depth on Lateral Stability of Cold-Formed Steel Beams of Corrugated Webs
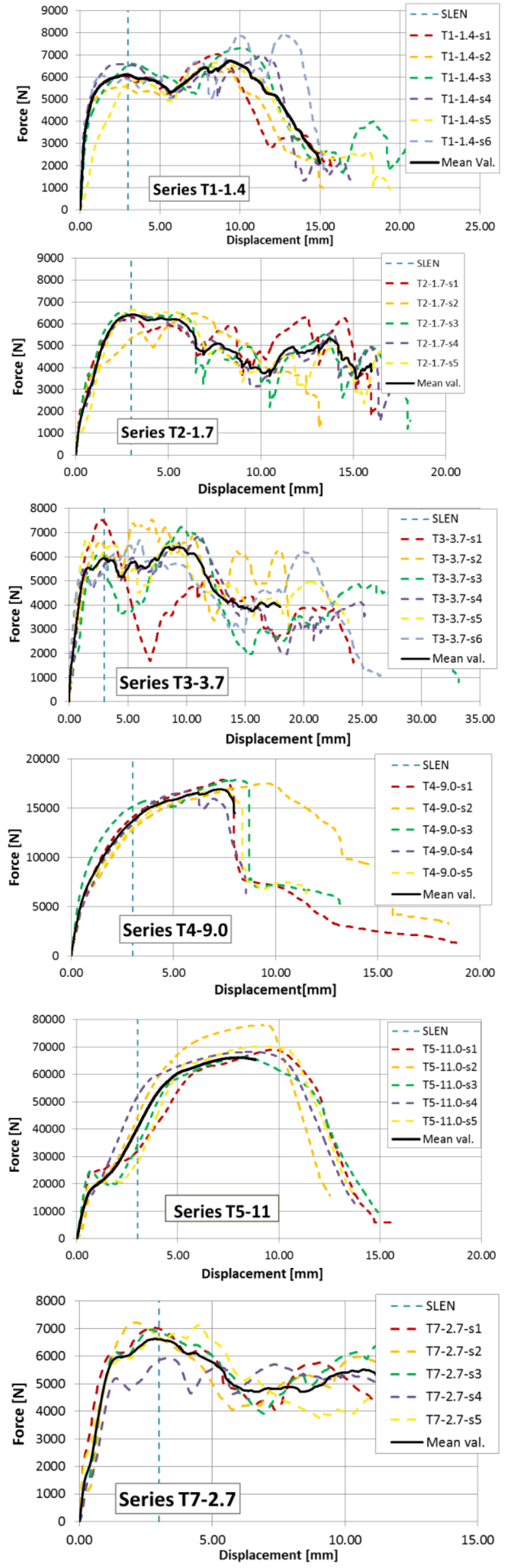

Fig. 5. Force-displacement curves for the tested connections
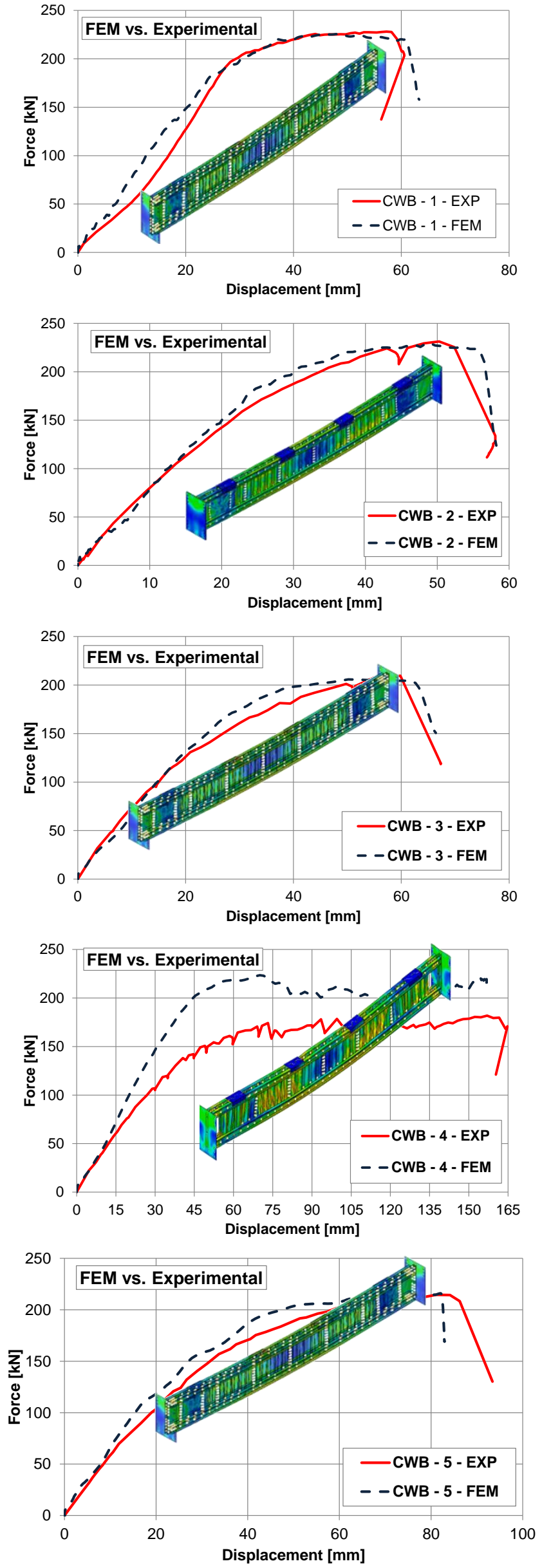

Fig. 6. FEM / Experimental load - displacement curves 
Based on the presented results, the FEM model can be considered as validated. Further, it has been applied to evaluate the behaviour and capacity of a beam of $12 \mathrm{~m}$ span, with trapezoidal shape, as shown in Fig. 7. The height of the beam at ridge was considered $900 \mathrm{~mm}$, while at eaves $1700 \mathrm{~mm}$. Details concerning the beam components are presented in Dubina et al. (2014). The lateral-torsional bucking has been prevented. Similar failure modes have been obtained as in case of the tested beams. Fig 7 presents the stress distribution and the load-displacement curve for this beam with trapezoidal shape. The maximum capacity is achieved at $389.12 \mathrm{kN}$ (i.e. corresponding to $5.4 \mathrm{kN} / \mathrm{m} 2$, considering a spacing of $6 \mathrm{~m}$ ) for $35 \mathrm{~mm}$ displacement.

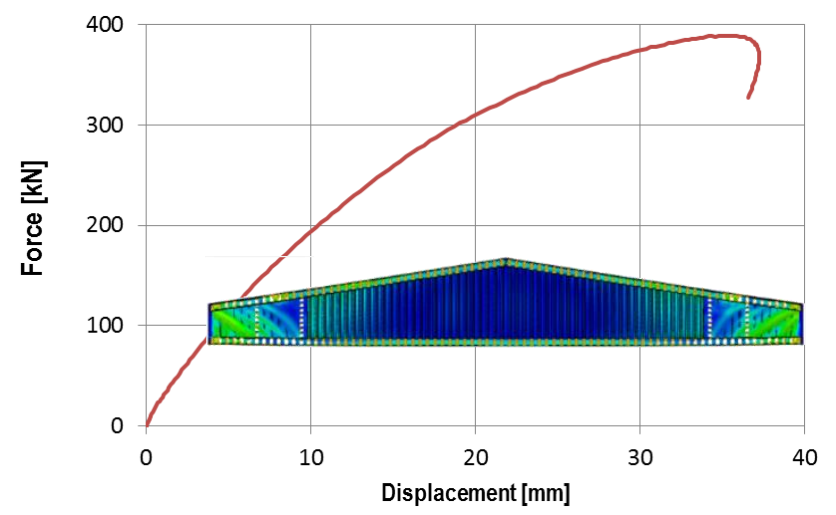

Fig. 7. Stress distribution and load-displacement curve for a $12 \mathrm{~m}$ span beam with corrugated web

Even good capacities can be obtained for larger spans, i.e. 16-18 $\mathrm{m}$ or more, the disadvantage of these trapezoidal beams is the height at the eaves and the difficulties in tailoring the corrugated sheets at the top flanges. In order to overcome these deficiencies, an alternative solution of parallel flanges sloped beams (e.g. pitched roof beams) was considered.

FEM model, correspondingly adapted, has been applied to evaluate the behaviour and capacity of these beams, taking as reference a pitched roof portal frame of $16 \mathrm{~m}$ span, with a $10^{\circ}$ slope, as shown in Fig. 8 (Dubina et al., 2014)).

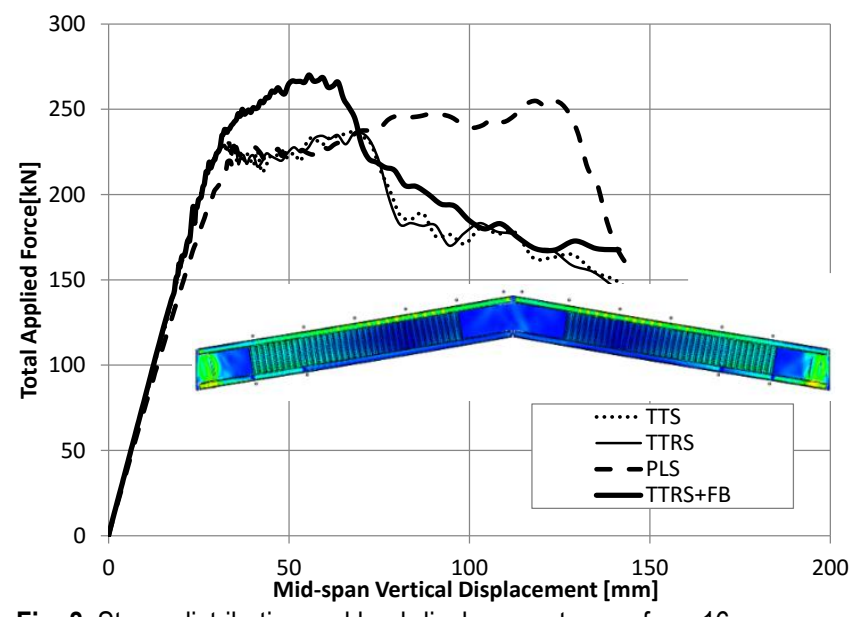

Fig. 8. Stress distribution and load-displacement curve for a $16 \mathrm{~m}$ span beam with corrugated web

The beam components are:

- back-to-back lipped channel sections for flanges $2 \times C 150 / 2.0$, steel grade S350GD+Z;
- corrugated web with the corrugation depth of $43 \mathrm{~mm}$ and the thickness of $0.7 \mathrm{~mm}-\mathrm{A} 45 / 0.7$, steel grade S320GD+Z;

- reinforcing shear panels - plates of $2 \mathrm{~mm}$ thickness and 1300 $\mathrm{mm}$ length, at the beam ends (ridge and eaves), steel grade S320GD+Z;

- self-drilling screws for flange-to-web connection - STP-6.3×25 ( 3 self-drilling screws per height of the profile);

- self-drilling screws for shear plates to end support with a nominal diameter - STP-5.5×25;

- self-drilling screws as seam fasteners for corrugated webs with a nominal diameter - STT-4.8×20 (16 self-drilling screws per height of the profile);

- M16 bolts class 8.8 for flanges to the end support connection ( 6 bolts for each flange); (8) the height of the beam was constant along the length, i.e. $1000 \mathrm{~mm}$.

Four types of lateral restraints have been considered in the analysis, i.e.

- pinned lateral supports at the top flange in the position of purlins (PLS);

- transversal translational springs at the top flange in the position of purlins, corresponding to axial rigidity of a Z200/2 purlin (TTS);

- transversal translational and rotational springs at the top flange in the position of purlins, corresponding to axial and bending rigidities of a Z200/2 purlin (TTRS);

- case no. 3 including fly bracings corresponding to the first purlin adjacent to the ridge (TTRS+FB). Fig. 9 presents the load-displacement curves for this beam with trapezoidal shape.

The maximum capacity for TTRS+FB beam is achieved at $270.16 \mathrm{kN}$ (i.e. corresponding to $2.81 \mathrm{kN} / \mathrm{m} 2$, considering a frame spacing of $6 \mathrm{~m}$ ) for $55.51 \mathrm{~mm}$ displacement.

\section{INFLUENCE OF CORRUGATION DEPTH ON THE LATERAL STABILITY OF BEAMS}

Based on the conclusions of the second beam, of $16 \mathrm{~m}$ span with parallel flanges, on the following, the influence of the depth of corrugation on the global behaviour is studied. In this sense, three different depths for the corrugated web have been chosen, i.e. 30 $\mathrm{mm}, 43 \mathrm{~mm}$ (presented above) and $85 \mathrm{~mm}$, in all the cases the thickness being $0.7 \mathrm{~mm}$. Case number (4) from the chapter above has been analysed and presented below. Also, it should be mention that in case of screws, the optimized solution used for beam CWB-5 was adopted, i.e. by adapting both the flange-to-web connections and seam fasteners to the distribution of shear stresses. Fig. 9 presents the force-displacement curve for the 30 $\mathrm{mm}$ depth of corrugation and the points 1-2-3 corresponding to the appearance of local failures.

Tab. 5. Force and displacements for characteristic points

\begin{tabular}{|c|c|c|c|c|c|c|}
\hline \multirow{2}{*}{ Point } & \multicolumn{2}{|c|}{$\mathbf{3 0} \mathbf{~ m m}$ corr. } & \multicolumn{2}{c|}{$\mathbf{4 5} \mathbf{~ m m}$ corr. } & \multicolumn{2}{|c|}{$\mathbf{~ m m}$ corr. } \\
\cline { 2 - 7 } & $\mathbf{F}(\mathbf{k N})$ & $\begin{array}{c}\boldsymbol{\Delta} \\
(\mathbf{m m})\end{array}$ & $\mathbf{F}(\mathbf{k N})$ & $\begin{array}{c}\Delta \\
(\mathbf{m m})\end{array}$ & $\mathbf{F}(\mathbf{k N})$ & $\begin{array}{c}\Delta \\
(\mathbf{m m})\end{array}$ \\
\hline 1 & 258.1 & 29.5 & 275.5 & 32.7 & 263.4 & 36.7 \\
\hline 2 & 291.2 & 41.1 & 279.8 & 46.3 & 293.3 & 43.4 \\
\hline 3 & 279.7 & 53.8 & 286.7 & 59.8 & 287.2 & 46.5 \\
\hline
\end{tabular}




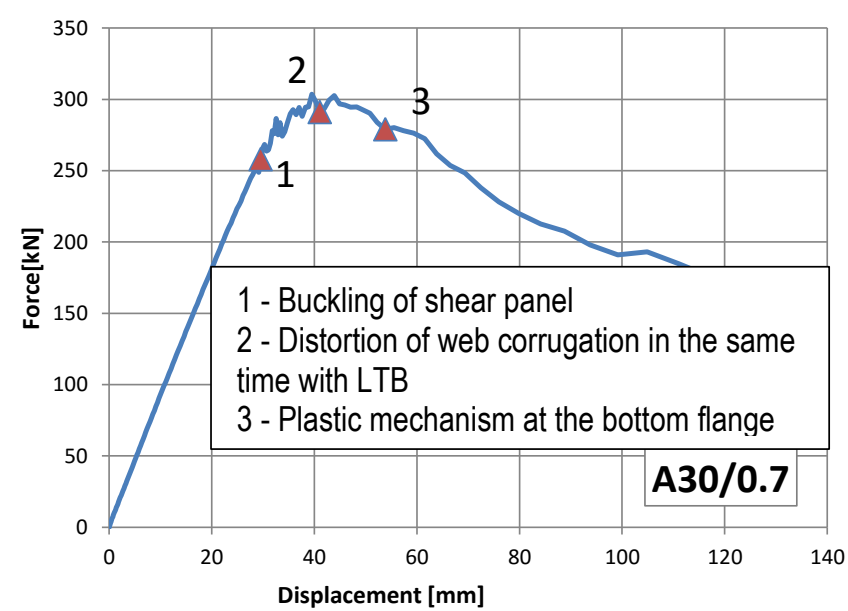

Fig. 9. Force-displacement curve for $30 \mathrm{~mm}$ depth of corrugation

Fig. 10 presents the distribution of stresses for the three characteristic points.

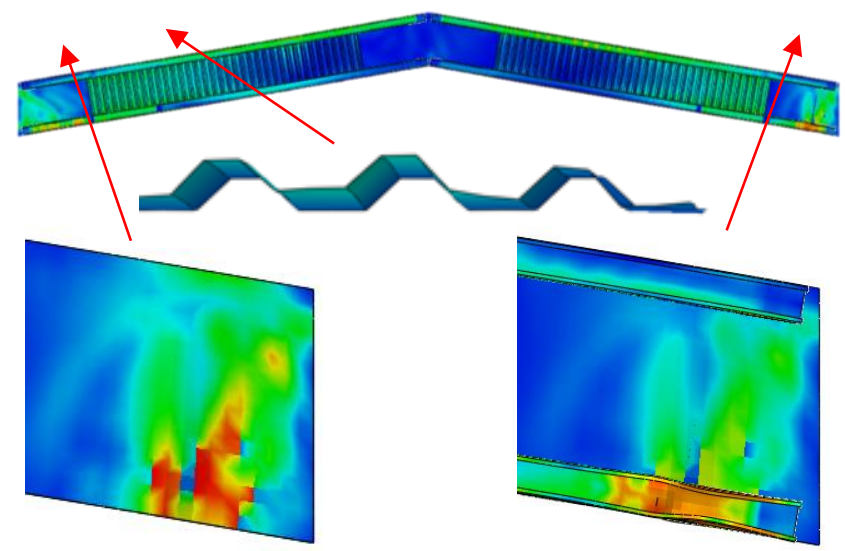

Fig. 10. Distribution of stresses for the three characteristic points

Fig. 11 and Fig. 12 present the force-displacement curves for the $43 \mathrm{~mm}$ and $85 \mathrm{~mm}$ depths and the corresponding points 1-2-3. The subsequences of appearance are the same as in the first case, but for different values of force/displacement (see Tab. 5). The distribution of stresses presented in Fig. 10 is almost the same as for the beam with $30 \mathrm{~mm}$ depth of corrugation.

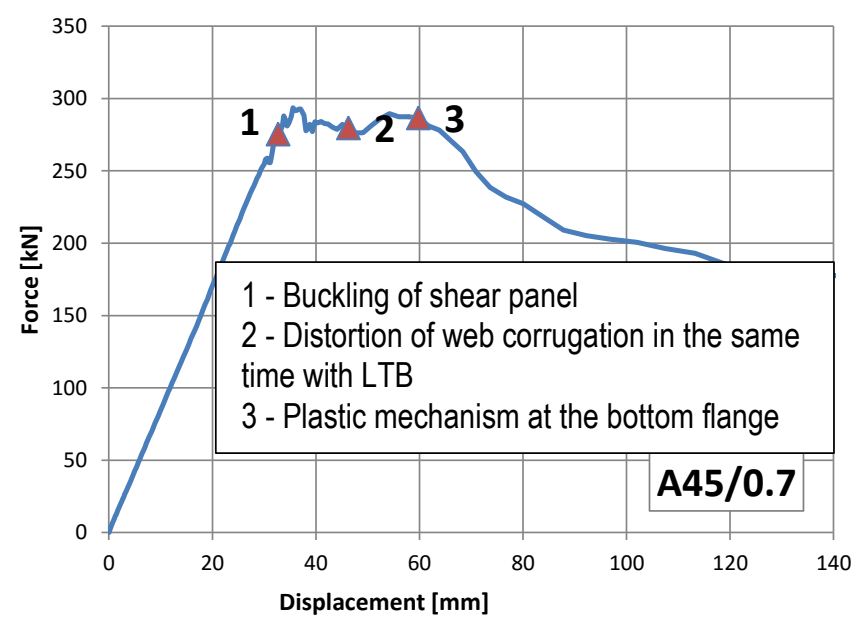

Fig. 11. Force-displacement curve for $45 \mathrm{~mm}$ depth of corrugation

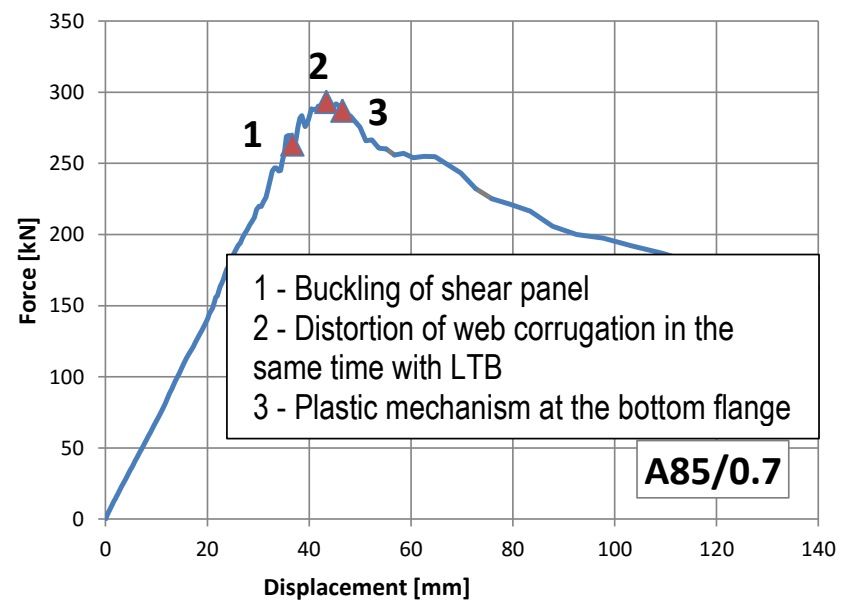

Fig. 12. Force-displacement curve for $85 \mathrm{~mm}$ depth of corrugation

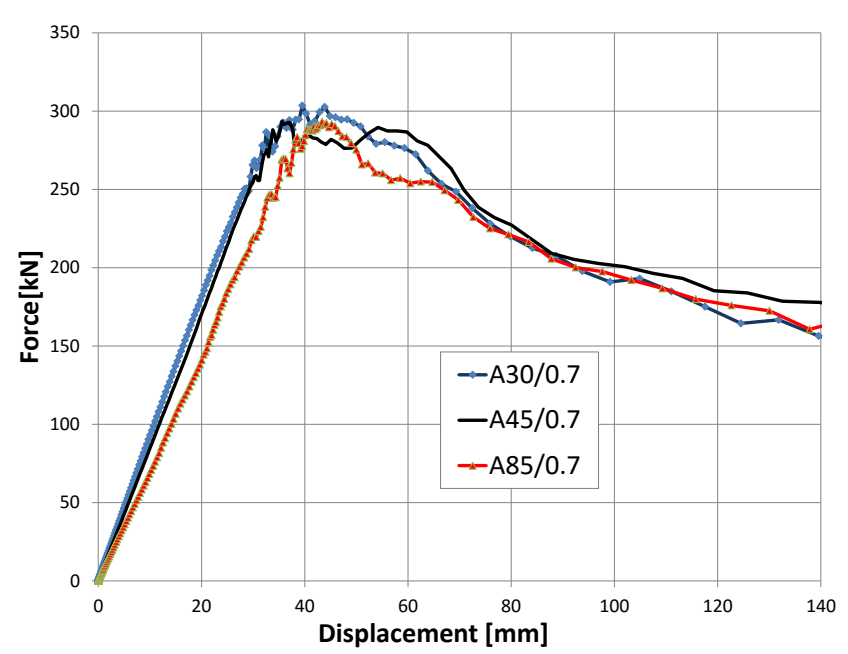

Fig. 13. Force-displacement curve for the three different depths of corrugated web

Plotting all three curves on the same graph, it is easy to see that curve for corrugation A85 has a reduced stiffness compared to the other two due to the fact the depth of the corrugations is more sensible to the end distortion of the corrugations. More, after reaching the maximum load the curve drop suddenly and a stable path can be seen due to the buckling coming from inplane loading of the web. The curves for corrugation A30 and A45 have the same stiffness, but the maximum force is lower in case of A45 and a "plateau" can be seen between points 1-2-3 (see Fig. 13 and Tab. 5).

Another aspect is related to the optimisation of screws used both as seam fasteners and for connecting the web to the flanges. A better distribution of self-drilling screws together with reduced thicknesses for the web will put better in evidence the influence of the sheeting.

\section{CONCLUSION}

A large experimental program carried out at the CEMSIG Research Centre (www.ct.upt.ro/centre/cemsig/) of the Politehnica University of Timisoara on five beams with corrugated webs with different arrangements for self-drilling screws and shear panels was presented. Very good agreement between numerical models 
and experimental ones have been obtained, in both failure modes and load-displacement curves.

A beam with parallel flanges, coming from a pitched roof portal frame of $16 \mathrm{~m}$ span, considering 4 types of lateral restraints have been numerically tested, in order to observe the potential for practical application of proposed technical solutions. The influence of corrugation depth has been particularly investigated in present study, by using three different depths, i.e. of 30,45 and $85 \mathrm{~mm}$. It can be observed that the capacity of these beams is almost the same, but for deeper corrugations, as effect of distortion, the deflection increases, while stiffness decreases. It is expected for thinner sheeting, the differences might be even more significant. The increase of ratios between pitch of seem fasteners and of flange-to-sheeting connectors vs. thickness of the web must be other parameters contributing to increase the influence of corrugation depth. On the aim of optimizing the technical solution for a mass production of such beams, the further investigations will focus on these aspects.

\section{REFERENCES}

1. Abbas H.H., Sause R., Driver R.G. (2006), Behavior of corrugated web I-girders under in-plane loads, Journal of Engineering Mechanics, ASCE, 132(8), 806-814.

2. Abbas H.H., Sause R., Driver R.G. (2007), Analysis of flange transverse bending of corrugated web I-girders under in-plane loads, Journal of Structural Engineering, 133(3), 347-355.

3. Briskham P., Blundell N., Han L., Hewitt R., Young K., Boomer D. (2006), Comparison of self-pierce riveting, resistance spot welding and spot friction joining for aluminium automotive sheet, $\mathrm{SAE}$ Technical Paper 2006-01-0774, doi:10.4271/2006-01-0774.

4. Dubina D., Ungureanu V. and Gîlia L. (2014), Cold-formed steel beams of corrugated web and built-up section chords, Proceedings of the 7th European Conference on Steel and Composite Structures EUROSTEEL 2014, 10-12/09, 429-430.

5. Dubina D., Ungureanu V., Gîlia L. (2015), Experimental investigations of cold-formed steel beams of corrugated web and built-up section for flanges, Thin-Walled Structures, 90, 159-170.

6. Dubina D., Ungureanu V., Gîlia, L. (2013), Cold-formed steel beams with corrugated web and discrete web-to-flange fasteners, Steel Constructions - Design and Research, 6(2), 74-81.

7. Guenfoud N., Tremblay R., Rogers C.A. (2010), Arc-Spot Welds for Multi-Overlap Roof Deck Panels, Twentieth International Specialty Conference on Cold-Formed Steel Structures, 535-549.

8. Jiho M., Jong W., Byung H.C., Hak-Eun L. (2009), Lateral-torsional buckling of I-girder with corrugated webs under uniform bending, Thin Walled Structures, 47(1), 21-30.

9. Kazemi Nia Korrani H.R., Molanaei S. (2010), The Effects of the Corrugation Profiles of the Web on the Lateral-Torsional Buckling Strength of the Inelastic I-Girder, World App. Sci. Journal, 8(5), 527-530.

10. Kövesdi B., Jáger B., Dunai L. (2012), Stress distribution in the flanges of girders with corrugated webs, Journal of Constructional Steel Research, 79, 204-215.

11. Landolfo R., Mammana O., Portioli F., Di Lorenzo G., Guerrieri M.R. (2009), Experimental investigation on laser welded connections for built-up cold-formed steel beams, Journal of Constructional Steel Research, 65, 196-208.

12. Landolfo R., Mammana O., Portioli F., Di Lorenzo G., Guerrieri, M.R. (2008), Laser welded built-up cold-formed steel beams: Experimental investigations, Thin-Walled Structures. 46(7-9), 781 . 791.

13. Moon J., Yi J., Choi B.H., Lee H.-E. (2008), Shear strength and design of trapezoidally corrugated steel webs, Journal of Constructional Steel Research, 65(5), 1198-1205.

14. Moon, J., Lim, N.H., Lee, H.E. (2013), Moment gradient correction factor and inelastic flexural-torsional buckling of I-girder with corrugated steel webs, Thin-Walled Structures, 62, 18-27.

15. Neagoie B., Ungureanu V., Dubina D. (2005), Beams with coldformed steel sections for flanges and corrugated web (in Romanian), Stability and Ductility of Steel Structures - Recent research, Academic Days, Timisoara, Romania, 27/05, 57-70.

16. Pasternak H., Robra J., Kubieniec G. (2010), New proposals for EN 1993-1-5, Annex D: Plate girders with corrugated webs, Codes in Structural Engineering, Joint IABSE-fib Conference, Dubrovnik, Croatia, 2, 1365-1372.

17. Sause R., Braxtan T.N. (2011), Shear strength of trapezoidal corrugated steel webs, Journal of Constructional Steel Research, 67(2), 223-236.

18. Snow G. (2008), Strength of arc spot welds made in single and multiple steel sheets, MSc Thesis, Blacksburg, Virginia, USA.

19. Wanniarachchi S. (2005), Flexural Behaviour of Cold-formed Steel Beams with Rectangular Hollow Flanges, PhD Thesis, School of Civ. Eng., Queensland University, Brisbane, Australia.

20. Yi J., Gil H., Youm K., Lee H. (2008), Interactive shear buckling behavior of trapezoidally corrugated steel webs, Engineering Structures, 30(6), 1659-1666.

21. Zhao W. (2005), Behaviour and design of cold-formed steel hollow flange sections under axial compression, $\mathrm{PhD}$ Thesis, School of Civ. Eng., Queensland Univ., Brisbane, Australia.

22. ABAQUS/CAE v6.7.1 [Computer software]. ABAQUS Inc., Pawtucket, RI.

23. ECCS 2008, The Testing of connections with mechanical fasteners in steel sheeting and sections, Publication 124, ECCS, Brussels, Belgium.

24. EN ISO 6892-1:2009. Metallic materials - Tensile testing - Part 1: Method of test at room temperature. CEN, Brussels.

25. EN1993-1-1:2005, Eurocode 3: Design of steel structures - Part 1-1: General rules and rules for buildings, CEN, Brussels.

26. EN1993-1-3:2006, Eurocode 3: Design of steel structures. Part 1-3: General Rules. Supplementary rules for cold-formed thin gauge members and sheeting, CEN, Brussels.

27. EN1993-1-5:2006, Eurocode 3: Design of steel structures - Part 1-5: Plated structural elements, CEN, Brussels.

28. RFSR-CT-2007-00038, Prefabricated steel structures for low-rise buildings in seismic areas (Precasteel), Final report, Research Fund for Coal and Steel, 2013.

29. US3444664A Patent, Ribbed web girder, Macomber Inc, Fink Jr. H. R., Scott V. P., http://www.google.com/patents/US3444664, 1967.

30. WO 00/17463, International Patent Classification E04C 3/07 (2000). Modular H-beam, BEN-VAUTIER S.P.A., Italy.

31. Zeman \& Co GmbH, Corrugated Web Beam, Technical Document, 2013 (www.zeman-steel.com/). 